\title{
Control the Size and Uniformity of Rock Fragmentation by Optimizing Firing Pattern in Open Pit Mine
}

\author{
Yoshiaki Takahashi $^{*}$, Takashi Sasaoka ${ }^{2}$, Sugeng Wahyudi ${ }^{2}$, Akihiro Hamanaka $^{1}$ and Hideki Shimada ${ }^{2}$ \\ ${ }^{1}$ Research Institute of Science for Safety and Sustainability, National Institute of Advanced Industrial Science and \\ Technology, Tsukuba, Japan \\ ${ }^{2}$ Department of Earth Resource Engineering, Faculty of Engineering, Kyushu University, Fukuoka, Japan \\ Email: yoshi-takahashi@aist.go.jp
}

\begin{abstract}
Rock fragmentation is one of the major concern in surface mining because of its strong influence on the efficiency and productivity of the mining operation. Although past researches show that the size of rock fragmentation can be controlled by optimizing blasting designs, the effects of blasting designs or prediction methods of the size of rock fragmentation have not yet been discussed enough yet. In addition, the research works only focused on the controll and prediction of means size of the rock fragmentation. However, they have not considered the uniformity of the rock fragmentation despite all the size of rock fragmentation sould be ideally same in terms of efficiency. Firing pattern including delay time is one of the blasting designs which can be easiliy altered and has low impact on the production. Therefore, the effect of firing pattern on both the size and uniformity of rock fragmentation was discussed in this study. The results showed that two directions of firing pattern had advantage in terms of both mean size and uniformity of rock fragmentation.
\end{abstract}

Keywords: Surface mining, rock blasting, rock fragmentation.

\section{$1 \quad$ Introduction}

In modern mining industry, rock blasting is the most commonly used method for rock mass breakage [1]. It has been adopted for not only mining but also civil engineering such as tunnels, highways and dams. This technique is one of the essential parts of working cycle in the open-pit mining excavation. Typical productions of mining industries such as coal and metal are key materials for other industries; therefore, to minimize the operation costs is extremely important for the development of our society with the recent decrease of such resources.

Since rock fragmentation strongly influences on the costs of drilling, blasting and the efficiency of all the subsystems such as loading, hauling and crushing in mining operations, it is considered as the most important aspect of production blasting. Large fragmentation or excess of fines can result in low efficient or profits of the mining operation [2]. Well designed blasting can contribute to the size that can be accommodated by the available loading and hauling equipment and crushing plant with little or no need for secondary breakage. For this reason, many researchers have studied the effect of blasting designs and prediction method of the size of rock fragmentation for the efficient blasting operation [3-5]. In addition to the mean size of rock fragmentation, the size distribution is also important point. In other words, all of the size of rock fragmentations is ideally same for efficient miming operation. However, many research works only focus on the control and prediction method of mean size of rock fragmentation.

Firing pattern including delay time is one of the blasting design, which generally set in order to reduce the level of blast-induced ground vibration [6-7]. In comparison to other blasting designs, it generally does not have obvious influence on the amount of recovered ore. That is to say, the guideline of controlling the size by delay time is established, resulting in efficient mining operation. Although several research works have reported that the size could be improve by optimizing the delay time [8], the effect of delay time on the size or distribution of rock fragmentation has not been discussed enough. In order to solve this problem, a series of field experiment was conducted in operating metal mine in Japan. This paper discussed that the effect of firing pattern on both mean size and distribution of rock fragmentation. In other words, the goal of this study is to obtain both ideal size and uniform size distribution of fragmented rock induced by blasting by optimizing firing pattern. 


\subsection{Overview of Field Experiment}

In order to discuss the effect of firing pattern on the size of rock fragmentation, a series of field experiment was conducted in operating metal mine in Japan. Table 1 shows the general blasting standards of the mine. Within the limitation of the detonator, the effect of four types of firing pattern was discussed in this field experiment. By using MS electrical detonator, two types of delay time: $25 \mathrm{~ms}$ and $50 \mathrm{~ms}$ were set and firing directions: one direction and two directions were also discussed. In the one row blasting, one firing direction was firing the blasting holes from edge to edge of the blasting hole (one direction) and the other one was firing from the center to the both edges (two directions). The concepts of four types of firing pattern were illustrated in Fig. 1. Moreover, in this experiment, after blasting, the photograph of fragmented rock was captured by digital camera for rock fragmentation analysis and the rock samples were collected at every face for the test of mechanical properties of rock.

Table 1. Blasting standard in test mine.

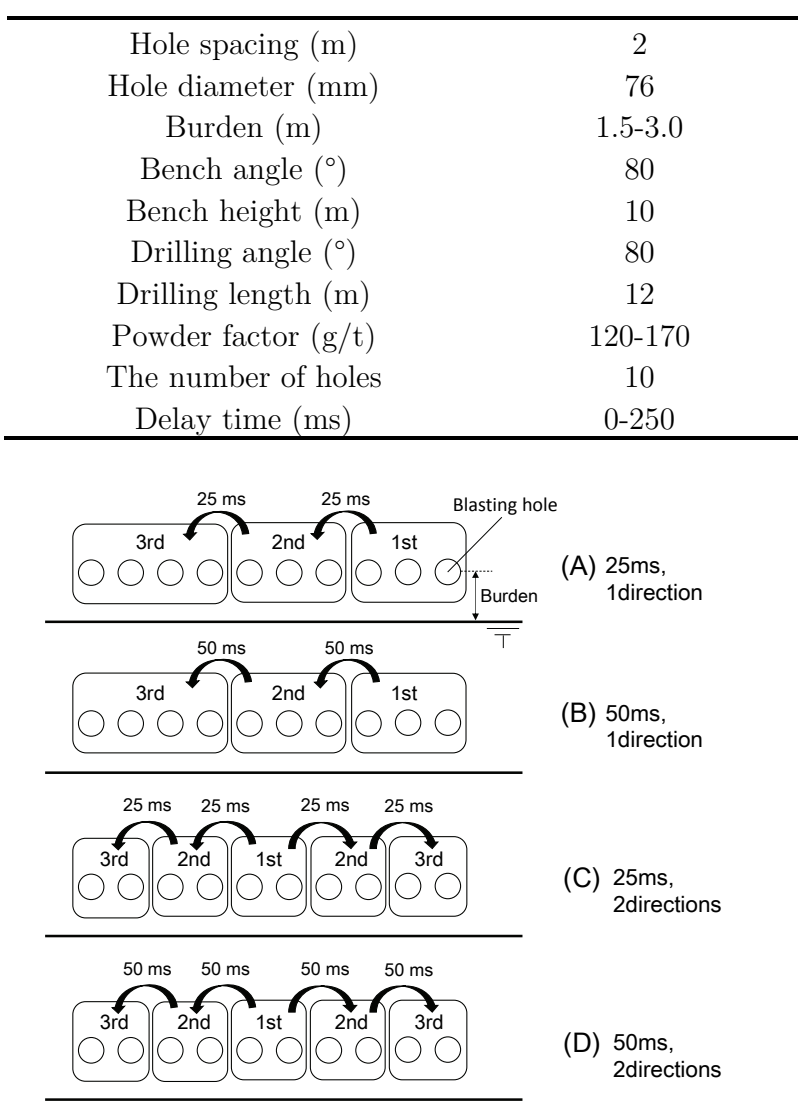

Figure 1. The concept map of four firing pattern.

\subsection{Analysis Method of Size Distribution of Blast-Induced Rock Fragmentation [2]}

Fragmentation assessment was performed by the image analysis on a basis of scaled photograph taken from the muck pile after blasting. Two balls with diameter of $24 \mathrm{~cm}$ were used as scale in the photograph. The balls were placed in the same vertical line down the fragmented rocks and they were preferably placed with one ball near the top of the rock fragmentation and the other near the bottom as shown in Fig.2. The balls should not be placed randomly in the fragmented rocks nor in a horizontal line across them. The photograph was taken by the digital camera as perpendicular to the surface of fragmented rocks as possible. After taking photographs, the photographs of rock fragmentation were analyzed by the software, Split-Desktop developed by Split Engineering. The outlines of visible rocks above a certain minimum resolution, $3 \mathrm{~mm}$ in diameter on the photograph, were traced by mouse. 
After the digital image was analyzed, the particle size distribution of fragmented rock was derived as shown in Fig. 3. In this research, the particle size at $50 \%$ of the gain size accumulation curve was defined as Xp50 as a representative value.

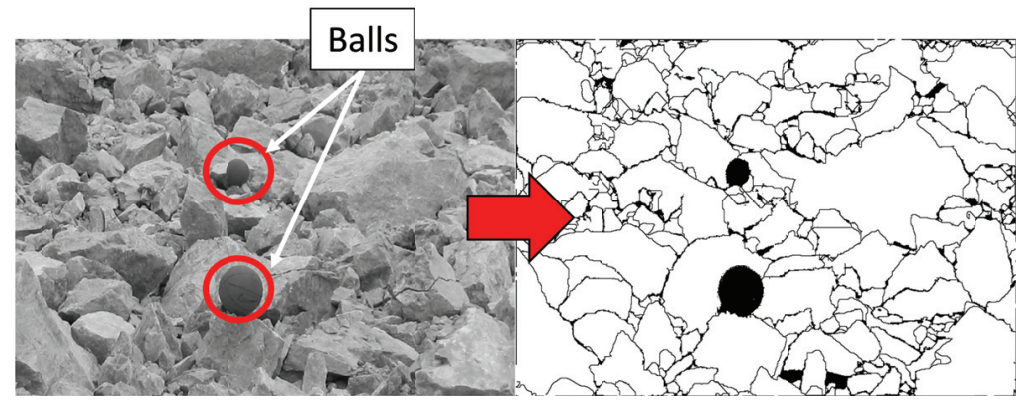

Figure 2. Outline of fragmentation analysis.

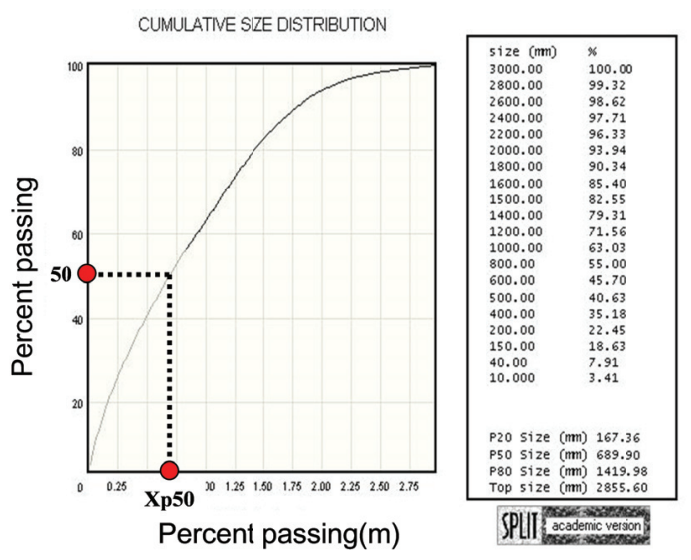

Figure 3. Particle distribution and Xp50.

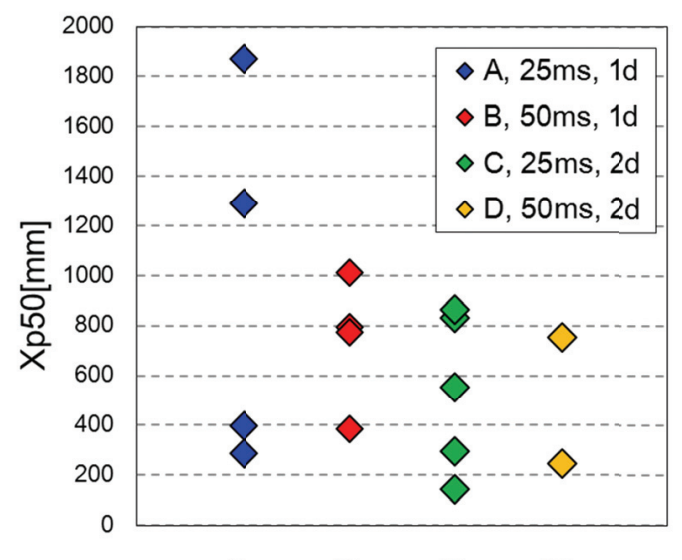

A $\quad$ B $\quad$ C $\quad$ D

Figure 4. The relationship between firing pattern and Xp50.

\section{Result and Discussion}

\subsection{The Effect of Firing Pattern on Mean Size of Rock Fragmentation}

First of all, the effect of delay time and firing pattern on the mean size of rock fragmentation is 
discussed. The relationship between each firing pattern and Xp50 is illustrated in Fig. 4. As can be seen in this figure, Xp50 in the case of $50 \mathrm{~ms}$ looks like small. Hence, the average of Xp50 of each firing pattern is calculate. The average Xp50 of pattern A, B, C and D are $961.3 \mathrm{~mm}, 742.1 \mathrm{~mm}, 537.6 \mathrm{~mm}$ and $500.7 \mathrm{~mm}$, respectively. Moreover, the average Xp50 of $25 \mathrm{~ms}$ (A and C) and $50 \mathrm{~ms}(\mathrm{~B}$ and D) of delay time are $670.5 \mathrm{~mm}$ and $661.7 \mathrm{~mm}$. These results suggested that the size of rock fragmentation can be reduced by applying $50 \mathrm{~ms}$ of delay time in this mine. There is a certain delay time which can be reduce the size of fragmented rock. This might be related to the velocity of the stress wave and the generation of new free face. On the contrary, the average Xp50 of one direction (A and B) and two directions (C and $\mathrm{D}$ ) of firing pattern are $861.7 \mathrm{~mm}$ and $482.7 \mathrm{~mm}$, respectively. It can be said that although delay time influence on the mean size of fragmented rock, the influence of firing direction is larger than that of delay time. Two directions of firing directions has good advantage of reducing the mean size of rock fragmentation. The result showed that the size of rock fragmentation could be effectively controlled by optimizing the firing direction.

\section{$2.2 \quad$ Uniformity of Rock Fragmentation}

By considering secondary breakage or mineral processing, all the size of obtained rock fragmentation is same ideally. That is to say, the uniformity of the size of rock fragmentation obtained by one blasting is also considerable issue for blasting operation. Figs. 5 (a) and (b) are the representative photographs of the muck pile after one direction and two directions blasting, respectively. As shown in these photographs, size distribution of rock fragmentation is different from each blasting pattern. In the case of firing patterns (A) and (B), the size of rock fragmentation is obviously different in the muck pile. That is to say, the size tends to be big around the area of start of firing point and the one is likely to be small around the area of the end of firing point. On the other hand, in the case of blasting patterns $(\mathrm{C})$ and (D), overall of the size is tends to be almost same. In case of one direction firing pattern, the size tends to be large around the area of start of firing point since stress wave interference is hard to occur around the area and at the end of firing point, stress wave interference help to reduce the size of rock fragmentation. On the other hand, stress wave interference equally occurred overall blasting area, resulting in homogenous size distribution.

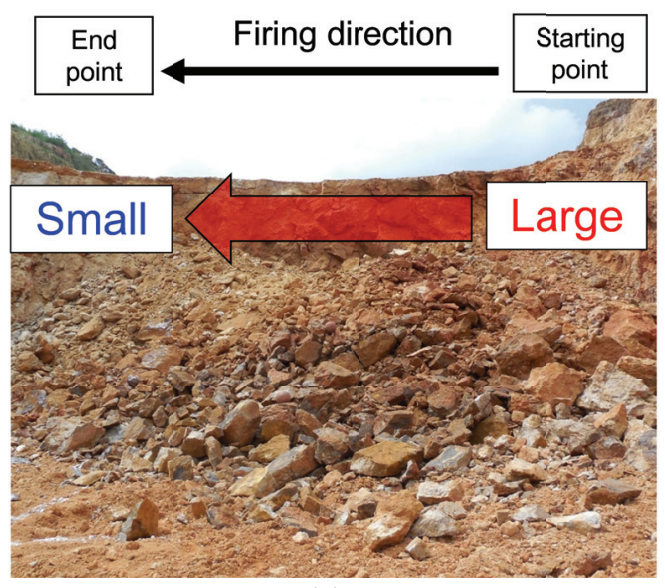

(a)

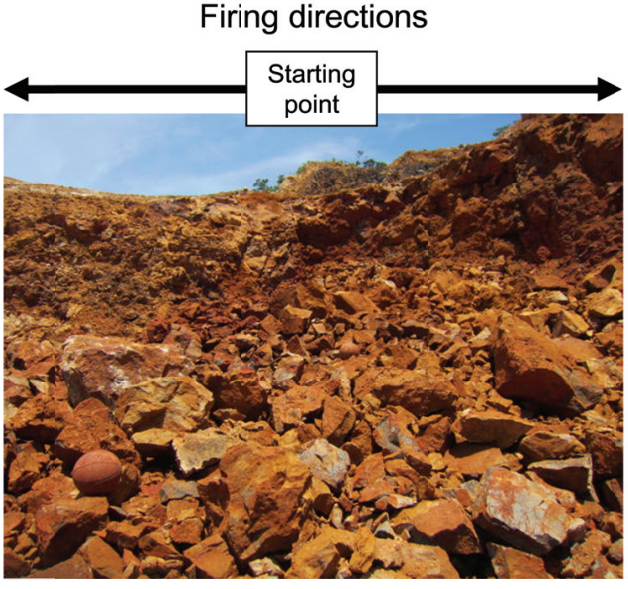

(b)

Figure 5. The representative photographs of muck pile after blasting (a) in the case of one direction of firing pattern (b).

\subsection{Prediction of the Distribution and the Size of Fragmentation in Delay Blasting}

Based on the discussion described above, the prediction method of uniformity of rock fragmentation in delay blasting is established in this section. In order to access the uniformity of the size of rock fragmentation, the uniformity of the distribution have to be quantitatively evaluated. Therefore, the 
uniformity coefficient is defined on a basis of uniformity coefficient which is generally used to classify the soil [9] as follow;

$$
n=\frac{X p 60}{X p 10}
$$

where, $\mathrm{n}$ is uniformity coefficient, Xp60 and Xp10 are the particle size at $60 \%$ and $10 \%$ of the gain size accumulation curve, respectively. In the field of soil classification, the range of the size distribution classified as wide when $\mathrm{n}$ is more than 10. On the other hand, the soil is judged as uniform when $\mathrm{n}$ is less than 10. Representative distributions and their uniformity coefficient are shown in Figs. 6 (a) to (c). In these cases, the value is 2.1, 15.1 and 20.3, respectively. By visual observations, the distributions are divided into three rank in this study. The divided rank is listed in Table. 2. The result of uniformity coefficient in each firing pattern is shown in Fig. 7. Moreover, the averages of uniform coefficient of pattern A, B, C and D are 27.7, 15.1, 5.65 and 7.98, respectively. Based on the results, it can be said that two directions of firing pattern can make the distribution more uniform in comparison to one direction of firing pattern. This might be because the formation of stress wave interference and generation of new free face symmetrically occur in the case of two directions of firing pattern. On the other hand, the behaviour of superposition of stress waves is different depending upon the place in the case of one direction of firing pattern, which result in ununiform size distribution. Two directions of firing pattern have good advantage of both distribution and mean size of fragmented rock. Although the required size is depends upon the operation, two directions of firing pattern is better to apply basically in terms of uniformity. Moreover, delay time should be selected depending upon the operation in order to efficiently control the size of fragmented rock.

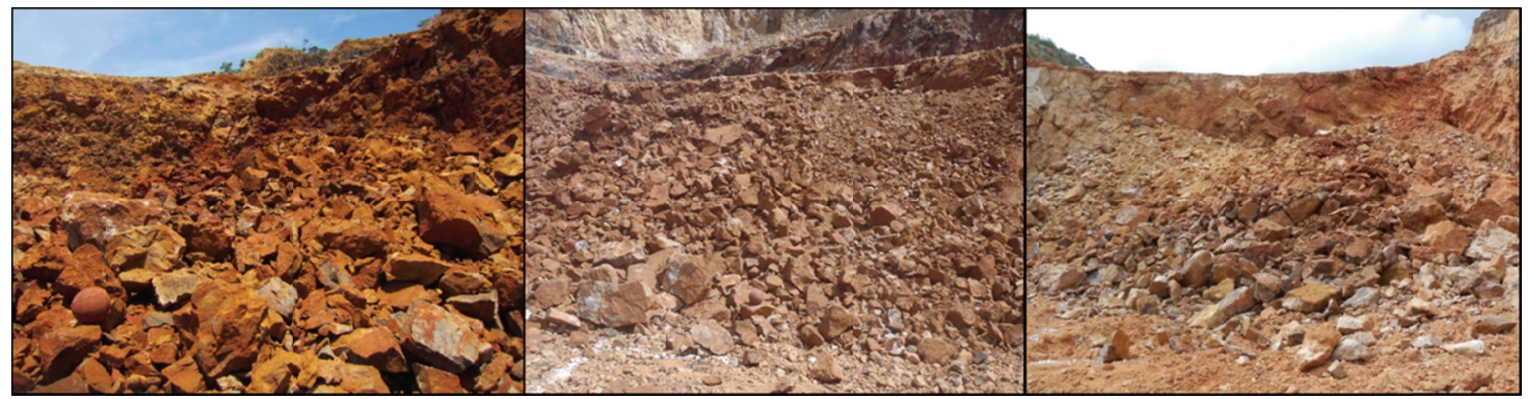

(a)

(b)

(c)

Figure 6. The representative photographs of muck pile after blasting (a) when $n$ is 2.1 , (b) when $n$ is 15.1 (c) when $\mathrm{n}$ is 20.3 .

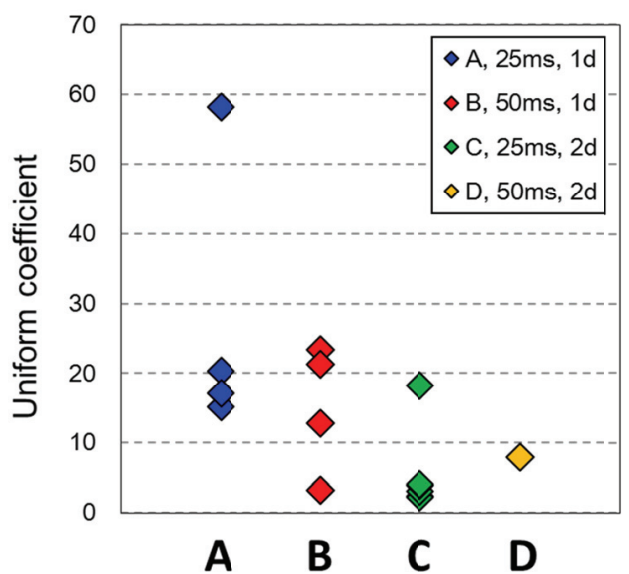

Figure 7. Uniformity coefficient of each firing pattern. 
Table 2. The rank of uniformity of distribution of rock fragmentation

\begin{tabular}{cc}
\hline Rank & $\mathrm{n}(-)$ \\
\hline Good & $0 \sim 10$ \\
Fair & $10 \sim 20$ \\
Poor & $20 \sim$ \\
\hline
\end{tabular}

\section{Conclusion}

The result of a series of field experiment showed that firing pattern has an obvious impact on both size and distribution of blast-induced fragmented rocks. Especially, firing direction strongly influence on both the distribution and size of blast-induced fragmented rocks. By applying two directions of firing pattern, the uniformity could be dramatically improved and the uniformity coefficient is less than 10 on average. On the other hand, delay time influence on the size of fragmented rocks, but the influence of the firing direction on the size is larger than that of delay time. In conclusion, two directions of firing pattern is basically applied and delay time should be set on a basis of the operation in order to obtain ideal fragmented rock induced by blasting.

Acknowledgement. The authors would like to express their thanks to the staffs of the mine. They also appreciate cooperation of Dr. Yuji OGATA, Dr. Shiro KUBOTA and Dr. Tei SABURI in Advanced Industrial Science and Technology

\section{References}

1. M. Monjezi, A. Bahrami and A. Y. Varjani, "Simultaneous prediction of fragmentation and flyrock in blasting operation using artificial neural networks," Journal of Rock Mechanics and Mining Sciences, vol. 147, pp. 476480, 2010.

2. T. Sasaoka, Y. Takahashi, W. Sugeng, A. Hamanaka, H. Shimada, K. Matsui and S. Kubota, "Effects of rock mass conditions and blasting standard on fragmentation size at limestone quarries," Open Journal of Geology, vol. 5, no. 1, pp. 331-339, 2015.

3. P. K Singh, M. P. Roy, R. K. Paswan, Md. Sarrim, S. Kumar, R. R. Jha "Rock fragmentation control in opencast blasting," Journal of Rock Mechanics and Geotechnical Engineering, vol.8, pp.225-237, 2016.

4. A. T. Elahi and M. Hosseini. "Analysis of blasted rocks fragmentation using digital image processing (case study: limestone quarry of abyek Cement Company)," International Journal of Geo-Engineering, 2017.

5. H. I. A. Shad, F. Sereshki, M. Ataei and M. Karamoozian, "Investigation of rock blast fragmentation based on specific explosive energy and in-situ block size," International Journal of Mining and Geo-Engineering, vol. 51, no.1, pp. 1-6, 2018.

6. X. Z. Shi and SH. R. Chen, "Delay time optimization in blasting operations for mitigating the vibration-effects on final pit walls' stability," Soil Dynamics and Earthquake Engineering, vol. 31, pp. 1154-1158, 2011.

7. M. Toma, S. Murata, M. Sakoda, H. Ishida, T. Shodai, T. Yuasa, Y. Nara and T. Ishida, "Optimal delay time of blasting caps to reduce vibration due to the infrasound caused by blasting," Journal of MMIJ, vol. 129, pp. 626634, 2013.

8. S. H. Cho and K. Kaneko, "Rock fragmentation control in blasting," Material Transactions, vol. 129, pp. 626634, 2013.

9. Japan Geotechnical Society, "Doshitsu sikenn kihon to tebiki," Journal of Rock Mechanics and Mining Sciences, Maruzen Publishing, 2010. 